\title{
CONTORNOS CONCEITUAIS DO COMUM E SUA RELAÇÃO COM O DIREITO: APROXIMAÇÕES TEÓRICAS
}

\author{
Fábio Gesser Leal ${ }^{1}$ \\ Gustavo Silveira Borges ${ }^{2}$
}

\section{RESUMO}

O presente artigo cuida do comum, conceito que ganhou destaque ultimamente e que se conecta ao discurso de resistência na busca de um mundo além da lógica neoliberal e proprietária. O objetivo é apresentar uma visão introdutória necessária para analisar os limites conceituais do comum e de que forma o Direito pode aparecer como articulador da sua regulação. Utilizou-se da metodologia dedutiva e da pesquisa bibliográfica. $\mathrm{O}$ estudo indica que o comum não possui um conceito homogêneo, que sua significação é ampla e de certa complexidade e que sua relação com o Direito é inarredável e exibida por diversos aspectos.

PALAVRAS-CHAVE: Comum. Conceito. Histórico. Resistência contra-hegemônica. Direito.

\section{CONCEPTUAL CONTOURS OF THE COMMON AND ITS RELATIONSHIP WITH LAW: THEORETICAL APPROACHES}

\begin{abstract}
This article takes care of the common one, a concept that has gained prominence lately and which connects itself to the discourse of resistance in the search for a world beyond the neoliberal and proprietary logic. The objective is to present an introductory vision necessary to analyze the conceptual limits of the common and in what way the Law can appear as articulator of its regulation. Deductive methodology and bibliographic research were used. The study indicates that the common does not have a homogeneous concept, that its meaning is broad and of a certain complexity and that its relation with the Right is inseparable and exhibited by diverse aspects.
\end{abstract}

KEYWORDS: Common.Concept. Historic.Counter-hegemonic resistance.Law.

\section{INTRODUÇÃO}

A questão do comum tem emergido nos últimos tempos, embora muito ainda se discuta quanto à clareza de seu conceito (CRUZ, 2017, p. 3). O termo, que se apresenta intimamente ligado ao discurso de resistência na busca por forças sociais, modelos alternativos, modos de organização e conceitos que forneçam esperança e solução para um

\footnotetext{
${ }^{1}$ Mestrando em Direito pela Universidade do Extremo Sul Catarinense - UNESC. Especialista pela Universidade do Sul de Santa Catarina - UNISUL em parceria com a Rede de Ensino Luiz Flávio Gomes - LFG. Graduado em Direito e em Administração de Empresas pelo Centro Universitário Barriga Verde - UNIBAVE. Professor titular na UNISUL. Assessor de Gabinete na Justiça Estadual de $1^{\circ}$ Grau em Santa Catarina. E-mail: fabiogesserleal@tjsc.jus.br.

${ }^{2}$ Pós-Doutor em Direito pela Universidade do Vale do Rio dos Sinos - UNISINOS. Doutor em Direito pela Universidade Federal do Rio Grande do Sul - UFRGS. Professor na Universidade do Extremo Sul Catarinense UNESC. E-mail: gustavoborges@ hotmail.com.
} 
mundo além do capitalismo, espelha um regime de práticas, lutas, instituições e pesquisas que abre portas para um futuro não edificado decisivamente na lógica neoliberal e proprietária, diverso do que hoje se experimenta (DARDOT; LAVAL, 2017, p. 11-18).

Nesse cenário, o presente artigo tem por objetivo geral fazer uma aproximação a respeito do comum, sem pretensão de esgotamento, isto é, com o intuito de apresentar uma visão introdutória necessária para analisar os limites conceituais, assim como de que forma o Direito pode aparecer como articulador da sua regulação.

Por se tratar de estudo oriundo do cenário da seara do Direito, privilegia-se um viés atrelado ao campo jurídico e, daí porque, mais atraente aos que militam nesta área. Porém, nada obsta a serventia do artigo para todos aqueles que, independentemente da área acadêmica ou profissional afetas, queiram inteirar-se da temática do comum.

Para cumprir sobredito objetivo geral, dividiu-se a abordagem do assunto em três partes: uma primeira, que cuida do tratamento conceitual do comum; uma segunda, que contempla seu tratamento histórico até a contemporaneidade; e, uma terceira, que trata da relação entre o comum e o Direito. Exibem-se como objetivos específicos, assim, esclarecer a conceituação do comum, situar suas categorias, identificar seu percurso no espaço-tempo até os dias atuais e apresentar o relacionamento entre o comum e o Direito.

A abordagem realizada justifica-se em face: (a) da crise vivenciada no mundo contemporâneo, representada e alimentada principalmente pela desigualdade socioeconômica da população e pela adoção de práticas capitalistas não sustentáveis, violadoras do meioambiente e ameaçadoras da vida atual e futura, em todas as suas formas; (b) da necessidade da adoção de políticas e medidas para reversão desse cenário, de pessoas passando fome, de concentração da riqueza na mão de poucos, de limitação do acesso aos bens realizadores da dignidade humana e de ofensas ao meio-ambiente e à vida considerada em sua amplitude; (c) da possível e determinante contribuição do comum para a construção de um caminho de mudança.

Com efeito, estudos apontam que a desigualdade no mundo apenas aumenta. Em relatório divulgado pela Oxford Committee for Famine Relief - OXFAM, por exemplo, descreve-se que a riqueza do $1 \%$ da população mundial é maior que a dos $99 \%$ restantes e que a riqueza de 42 pessoas é a mesma que a dos 3,7 bilhões mais pobres (OXFAM, 2017).

A liberdade do e pelo capital impulsionou mudanças nos últimos anos que desaguaram no aprofundamento negativo do distanciamento entre ricos e pobres, na geração de mais pobreza absoluta e relativa e no caminhar oposto ao ideal de construção de um mundo 
mais justo e equilibrado (CATANNI, 2009, p. 547), conferindo autoridade à conclusão de que o capitalismo é movido por uma busca patológica de poder e lucro (BAKAN, 2008).

O modelo desenvolvimentista em que o lucro é o bem supremo tem custos sociais e ambientais inevitáveis (SCHEEFFER, 2008, n. p.). No aspecto social, as desigualdades criadas são divisoras e, dependendo da extensão, podem concretamente comprometer não somente as condições de bem-estar e de desenvolvimento humano, como também os laços de solidariedade, de coesão coletiva e de ordem civil, a soberania dos Estados, o funcionamento das instituições, a eficiência dos sistemas econômicos e as possibilidades de crescimento mais inclusivo e sustentável (REBOUÇAS; PARENTE, 2018, p. 187). Já na perspectiva ambiental, a natureza é mercantilizada e degradada em detrimento do direito de vida em um ambiente sadio e livre de poluição (OLIVEIRA, 2014, p. 7).

Dedecca (2009, p. 1), analisando documentos da Organização das Nações Unidas ONU, da Organização Internacional do Trabalho - OIT e da Organização para a Cooperação e Desenvolvimento Econômico - OCDE, destaca que a dinâmica da economia atual vem produzindo uma distribuição desigual de resultados, seja em países desenvolvidos ou em desenvolvimento, e que, portanto, é preciso pensar em políticas que levem a uma correção dessa rota, já que a redução da desigualdade não seria e não será um resultado natural.

O caráter cogente da busca por uma saída para a reversão do quadro de crise, que agora se apresenta agravado, já era no início dos anos 2000 enunciado por Comparato (2001, p. 192-194), para quem restava clara a urgência da construção de um mundo novo, de uma civilização garantidora do direito à felicidade e contraposta ao capitalismo.

Nessa intelecção, a guinada para a prosperidade humana com vida digna para todos e garantia de um planeta sustentável pode residir na lógica do comum, enxergado como semente de uma sociedade futura não limitada à repetição dos esquemas do passado (HARDT; NEGRI, 2016, p. 255; SILVA, 2018, p. 63).

Inarredável, portanto, que seja encarada com seriedade a busca de alternativas à racionalidade capitalista hegemônica e suas consequências, o que passa, também, pela alocação prioritária dos estudos nesse sentido no âmago das diligências teóricas e acadêmicas, motivo pelo qual se desvela, uma vez mais, a relevância do objeto do presente artigo.

A reflexão em questão tem o intuito de buscar responder às seguintes indagações: qual o tratamento conceitual do comum? Como se articulam o comum e o Direito e é possível se falar em uma ordem jurídica do comum? 
Utilizou-se a metodologia dedutiva, aplicando-se a pesquisa bibliográfica com base na literatura nacional e estrangeira acerca da temática.

\section{TRATAMENTO CONCEITUAL DO COMUM: ESCLARECENDO E} SITUANDO SUAS CATEGORIAS

O tratamento conceitual do comum não é tarefa de somenos complexidade. Muito se tem indagado no tocante à clareza do conceito e suas categorias (CRUZ, 2017, p. 3), ficando tal ambiência bem refletida na obra de Medeiros (2017, p. 2) e na análise feita por Ruschel e Portanova (2018) no artigo intitulado "Global commons e confusão gerada a partir da nomenclatura: esclarecendo os diferentes conceitos dos comuns".

Não obstante, para o fim proposto no presente artigo, de se proporcionar uma visão introdutória necessária acerca do comum, apresenta-se indispensável o enfrentamento da questão, o que se passa a fazer.

Para Jean-Luc Nancy, segundo Mendes (2012, p. 142), o comum não é privado, nem coletivo; não é separação, nem totalização; não é realização política, nem substância. Ele é o “dado primeiro", "condição ontológica do ser", pré-requisito e possibilidade de "ativar" qualquer política e igualmente de limitá-la. Não pertence à política, mas surge “antes” dela.

Percebe-se na compreensão acima explicitada um viés transcendental. Realmente, na dicção de Medeiros (2017, p. 2), Nancy concebe o comum como aquilo que surge entre seres postos em comunicação, entre seres que compartilham sua existência, o "ser-em-comum", entendendo que, assim, trata-se de algo que antecede ao ser e que, logo, não é produzido, já que está na própria essência do indivíduo.

Nesse aspecto, Mendes (2012, p. 145) consigna que a posição de Nancy é importante e merece reflexão, mas afirma que "é preciso avançar para uma compreensão que aproxime comum e política, que tome a produção do comum com um verdadeiro processo antagonista".

Tal aproximação pode ser visualizada nas formulações de Hardt e Negri (2016), os quais reconhecem o comum, também tratado por eles, em diversas passagens, como bem-estar comum, como algo constituído por recursos e práticas que se efetuam para além do que é classificado como público e privado, socialista e capitalista. E relacionam o comum à multidão, na medida em que esta é entendida como um constante processo de transformação alicerçado naquele, no contexto de um modelo de produção econômica biopolítica. A 
multidão e seu fazer constituem-se compondo no comum as subjetividades singulares que resultam desse processo.

Hardt e Negri (2016, p. 140 e 236) fazem, ainda, uma identificação conceitual do comum dividindo-o em duas categorias principais: a primeira, denominada "comum natural" ou "comum material", representada pela terra, a água, o ar, os frutos da terra e por todas as dádivas da natureza; a segunda, batizada de "comum artificial", representada por elementos que não se prestam a uma lógica da escassez, como as linguagens sociais, as práticas que são estabelecidas, os modos de sociabilidade que definem relações, os códigos comuns, a produção de ideias e o conhecimento gerado, as imagens, etc. A primeira categoria é relacionada a um sentido de limitação; a segunda, a um sentido de promoção.

Sobre as definições dos autores em comento, todavia, Cruz $(2017$, p. 8) observa a existência de uma lacuna. Conforme a autora, em que pese Hardt e Negri apresentarem um conceito de comum já relacionado a uma prática construtiva, não houve distinção clara entre as práticas e os recursos aos quais se referem.

Uma melhor diferenciação parece ter sido alcançada por Pierre Dardot e Christian Laval na obra "Comum: ensaio sobre a revolução no século XXI". Os autores franceses deixam assentado que este vocábulo deve ser reservado para ser entendido primordialmente como um princípio político representativo de lutas e a partir do qual comuns devem ser construídos, preservados e ampliados, e não como um objeto, propriedade ou característica de uma coisa que constitua sua essência. Por outro lado, afastam a significação de "bens comuns" ou de "bem comum" das noções de comum e de comuns, atrelando este último termo não à designação do que é comum (que se pode dizer, todavia, que acaba de modo indireto integrando a intelecção do conceito de comuns, por ocupar o espaço institucional gerado pela prática comunizadora), mas à designação daquilo de que se encarrega uma atividade que põe algo em comum (DARDOT; LAVAL, 2017, p. 17, 53-54 e 617-619).

Dardot e Laval (2017. p. 35-42) sublinham que é necessário evitar qualquer forma de reificação do termo comum (tratamento do conceito como um objeto, fim ou coisa), o que impõe ir de encontro às principais tradições que influenciam as representações sobre o conceito, como a tradição teológica (representação de comum como orientação de perseguir da norma superior do "bem comum"), a tradição jurídica (noção de comum atrelada a uma coisa que pode ser classificada dentro de uma categoria de bens) e a tradição filosófica (entendimento do comum como algo universal ou então como algo insignificante, banal). $\mathrm{Na}$ interpretação de Silva (2018, p. 68): 
Essa noção dos comuns, destarte, recusa qualquer substancialismo em sua definição. Os comuns, como substantivo e materialização do princípio do comum, devem ser instituídos. Não existem comuns "por natureza", eles só se constituem através de uma prática constante de pôr em comum ou de fazer-comum. Laval e Dardot nomeiam essa prática de "práxis instituinte do comum".

Nesse caminhar, assinala Mendes (2012, p. 171-172), o comum não é apenas uma ideia, mas um movimento real, uma verdadeira possibilidade de vivência, sem mediações de qualquer natureza, de novas formas de relação, cooperação, afeição, produção e vida, que carrega consigo uma nova ética, experimentada por novas subjetividades que resolveram "virar as costas" para o capitalismo de mercado e para o socialismo real.

A intelecção do comum pode ser levada a efeito, ainda, pela perspectiva de David Bollier. Discorre o autor que o comum é mais do que resistência, é instrumento de inovação social, é uma categoria cultural e prática que procura ver o mundo em termos diferentes. É basicamente uma ordem econômica e social que afirma que outro mundo é possível e que podemos construí-lo adotando um paradigma prático para um governo autônomo, para a gestão de recursos e para o bem-viver (BOLLIER, 2014, p. 8-25).

Bollier, outrossim, delimita os comuns afirmando que referido conceito inclui recursos físicos e intangíveis de todo tipo, sendo identificado com maior precisão por um modelo que combina uma comunidade determinada e um conjunto de práticas sociais, valores e normas promovendo a gestão desses recursos (BOLLIER, 2014, p. 26).

Segundo Cruz (2017, p. 10), Bollier permite uma interpretação mais específica do que seriam os comuns, uma vez que lista uma série de recursos e processos geridos de forma coletiva que estão hoje ameaçados pela grande onda de privatizações e cercamentos (enclosures) ocorridos nas últimas décadas, tais como o compartilhamento de sementes das mulheres de Erakulapally, o sistema operacional GNU/Linux, a construção de uma rede de conhecimento em sítios eletrônicos com o Wikipédia, a produção acadêmica nas universidades e até mesmo a gestão de uso das ondas em Oahu, Havaí.

Para o adequado tratamento conceitual do comum, impende aclarar, ainda, algumas outras categorias relacionadas ao termo, as quais são frequentemente abordadas em escritos a respeito da matéria.

Primeiramente, deve ter lugar a conceituação de "bens comuns" e de "bem comum". Os "bens comuns" referem-se a uma classificação para além dos bens públicos e privados e podem ser identificados pela noção de bens ou recursos naturais ou artificiais compartilhados (uso rival e não exclusivo), como a água, o ar, uma praça, um parque. São traduzidos tradicionalmente pela expressão commons e também podem reportar-se ao fenômeno das 
"terras comunais". Já a categoria "bem comum" pode representar o singular do conceito "bens comuns" ou ter a si atribuída uma noção filosófica da busca de uma situação melhor para a coletividade, de uma condição benéfica geral (BERNARDES, 2017; DARDOT; LAVAL, 2017; MENDES, 2012; RUSCHEL; PORTANOVA, 2018).

“Terras comunais" é expressão que tem origem nas terras de populações camponesas da Inglaterra. A partir do século XIII, muitas dessas terras restaram transformadas em propriedades latifundiárias em processos de cercamentos (enclosures) para a formação de áreas de criação de animais, o que causou revoltas camponesas. Nos dias atuais, "terras comunais" ainda são encontradas e traduzem a noção de terras compartilhadas em um sistema de gestão realizado por grupo de pessoas vivendo dentro de uma propriedade comum (RUSCHEL; PORTANOVA, 2018, p. 296).

Outro termo que merece elucidação é commoning. Este pode ser entendido como o comum em ação, como um fazer-comum, exibindo que os comuns não existem como elemento à margem da comunidade que os gera e desfruta, mas sim representam um recurso que se converte por meio de um processo ativo de trabalho e regulamentação. E, nessa compreensão, exsurge ainda a expressão commoner, traduzida como comuneiro, que deve ser entendida como uma pessoa que produz o comum (CRUZ, 2017; LINEBAUGH, 2013).

Anticommons, a sua vez, é termo relacionado à Tragédia dos Anticomuns, desenvolvida por Michael Heller. Nessa teoria, que é analisada por seu autor sob o ponto de vista da propriedade privada e trata da subutilização ou desperdício de um recurso, a noção de “anticomuns", em contraposição à noção de comuns, é verificada quando há mais de um proprietário sobre um recurso limitado e a cada um é atribuído o direito de excluir os demais, sem que nenhum tenha a totalidade do direito sobre o recurso, mas com cada um possuindo parte dos respectivos direitos. Se não houver unanimidade de vontade, o recurso acabará por não ser utilizado ou subutilizado (RUSCHEL; PORTANOVA, 2018, p. 298).

Por "bem comum da humanidade" compreende-se uma elevação em relação à categoria dos "bens comuns", de sorte a prescrever algo em caráter mais geral, envolvendo os fundamentos da vida coletiva da humanidade no planeta: a relação com a natureza, a produção da vida, a organização coletiva (política) e a leitura, a avaliação e a expressão do real (cultura). A expressão em questão inclui os conceitos de "bens comuns" e o de "bem comum" em suas aplicações concretas e abrange a produção e a reprodução da vida na escala de toda a humanidade (HOUTART, 2011). 
Alfim, é preciso definir o que se tem depreendido a partir da expressão global commons. E, nesse mister, tem-se que se trata de conceito identificador de todos aqueles espaços de livre uso e acesso que não pertencem a nenhum Estado e sobre os quais nenhuma nação pode exercer direitos soberanos. São espaços que podem ser usados livremente por qualquer nação, a exemplo do alto mar, da atmosfera, da antártica e do espaço sideral (RUSCHEL; PORTANOVA, 2018, p. 296).

Examinados os contornos conceituais do comum, passa-se, doravante, ao tratamento de seu percurso histórico.

\section{ITINERÁRIO HISTÓRICO DO COMUM}

A discussão a respeito da questão do compartilhamento de bens e recursos é bastante antiga, já estando presente em Aristóteles (PERALTA, 2010, p. 63).

Na sociedade pré-romana, sobredita temática também encontrou tratamento, já que a maior parte da terra era de propriedade comum e usada conforme as necessidades de povos seminômades pastoris ou semipastoris, os quais resolviam seus conflitos patrimoniais não com base em postulados proprietários de vencedor e vencido, de certo e errado, mas com fundamento em soluções conciliatórias voltadas para a manutenção da convivência comunitária (CAPRA; MATTEI, 2018, p. 84-85).

A noção do comum, ademais, existiu igualmente na Roma antiga, em que um dos tipos de propriedade existentes era a res communes, a coisa pertencente a toda a comunidade (FIGUEIREDO, 2014, p. 28).

Da sociedade romana para cá, entretanto, gradativamente os bens e recursos comuns foram sendo transferidos para a propriedade pública ou privada, seja por meio de expedientes jurídico-governamentais formatados para tanto, seja por meio dos cercamentos privados baseados no poder e na força (CAPRA; MATTEI, 2018, p. 85-92).

Esse processo, contudo, não foi pacífico, gerando lutas de resistência, como as Rebeliões Comuneras de Castela, na Espanha, durante o século XIV (CERVEIRA, 2013).

A "pilhagem" realizada pelo Estado ou pelo setor privado daquilo que até então era de domínio comum teve seu exemplo mais notório do processo de cercamento privado de terras anteriormente de uso comum ocorrido na Inglaterra, entre os séculos XV e XIX (CAPRA; MATTEI, 2018, p. 91-93). 
No Brasil, Lima e Lopes (2018) visualizam no vilarejo de Canudos, na Bahia do final do século XIX, uma experiência representativa do comum e de sua desconstituição pelo poder dominante (episódio da Guerra de Canudos).

Já sob o contexto do neoliberalismo e da sociedade capitalista, a transferência de bens e recursos de uso comum e de espaços e serviços públicos para a propriedade pública e privada, qualificada por Pastor (2013, p. 41) como o "grande saque", permaneceu vívida, tendo seus horizontes ampliados em face das possibilidades geradas pela globalização.

Nessa ambiência, é no final do século XX que a abordagem do comum, como racionalidade representativa da resistência contra-hegemônica ao ideal neoliberal, passa a despontar e ganhar relevo. Nas palavras de Bernardes (2017, p. 24):

\begin{abstract}
Especialmente a partir do final da década de 1960, quando o problema ambiental impulsionou o surgimento de uma ecologia política através da inserção nos discursos políticos nacionais e internacionais das questões ambientais e ecológicas, o tema do comum assume um papel relevante em diversas pesquisas, sobretudo do ponto de vista dos chamados bens comuns, a serem preservados e gestionados. A ecologia política, assim, torna-se um campo de estudos em que o comum ganha visibilidade, desafiando as instituições modernas, moldadas principalmente sobre os paradigmas da cisão homem/natureza e da propriedade, pública ou privada, e trazendo ao campo do direito um desafio que parece, sobre muitos aspectos, intransponível.
\end{abstract}

O término dos anos 1980 trouxe consigo a intensificação do estudo do comum por diferentes campos do conhecimento (MEDEIROS, 2017, p. 1), o que, dentre outros fatores, pode-se afirmar que ocorreu em função do fortalecimento de uma perspectiva anticapitalista, alavancada a partir da crítica ao comunismo (TEIXEIRA, 2017).

Nos anos 1990, a genealogia do comum é decisivamente marcada pelo surgimento, na maior parte do mundo, de grupos militantes e correntes de pensamento que fortemente retomaram o fio da contestação da ordem dominante, ressaltando os efeitos corrosivos do neoliberalismo e a imprescindibilidade de uma nova ordem mundial, fundada em princípios que não fossem rendidos à concorrência, ao lucro e à exploração abusiva dos recursos naturais. A desgraça dos regimes comunistas, a destruição do socialismo pela apropriação estatal de todos os meios de produção e da administração pública e a insatisfação com a lógica neoliberal abrem, pois, caminho para a consolidação do tema do comum, registrado nos movimentos altermundialistas e ecologistas, que tomaram como referência o antigo termo commons (DARDOT; LAVAL, 2017, p. 17, 62 e 101).

Esse fenômeno de resistência, movimentos e lutas espraiou-se por diversas partes do globo, sendo também haurido pelo constitucionalismo latino-americano. De fato, segundo Wolkmer e Scussel (2018, p. 82), embora o modelo constitucional latino-americano tenha se comprometido historicamente com o estabelecimento do sistema capitalista, emerge do 
cenário recente da América Latina, a partir da década de 1990, um novo ciclo civilizatório de lutas em prol do comum, inaugurando-se um novo constitucionalismo.

Os principais acontecimentos que gravaram o percurso do comum a partir da década de 1990 são resumidos com propriedade por Cava (2015):

\begin{abstract}
A genealogia do comum pode ser traçada, em primeiro lugar, no ciclo de lutas (sentido muito amplo!), ou melhor, em dois, um ciclo longo e um curto, cuja memória viva se pode remontar. O ciclo longo dispara com a insurreição zapatista em 1994, hibridação entre guerrilha armada e midiática, política e estética, indígena e devir-índio, local e global, devir-sul e pós-colonialismo, formando um novo tecido criativo de resistência a pautar toda a geração. $\mathrm{O}$ zapatismo se desdobra numa sequência global de revoltas contra o neoliberalismo, leva à Seattle, Praga, Gênova, aos Dias de Ação Global, ao altermundismo e à primeira leva dos Fóruns Sociais Mundiais - FSM, no Brasil e na Índia. O ciclo curto irrompe com as revoluções árabes em dezembro de 2010. Nada a ver com revoltas pelo pão, que a tentam remeter a um caráter medieval, nem com revoluções liberais contra o autoritarismo dinástico das ditaduras, que a colocam 200 anos no passado europeu. Tais apreensões colonialistas contornam o fato que, de Túnis à Praça Tahrir, da Líbia ao Bahrein, as revoluções árabes foram lutas de novo tipo, na alta intensidade das redes, hibridações e positividades: comum. Os ventos primaveris do Mediterrâneo levaram os esporos do norte da África ao sul da Europa, onde pipocaram as 600 acampadas do movimento do 15 de Maio, que depois saltou o Atlântico provocando o Occupy Wall Street e milhares de ocupas pelo planeta inteiro. Depois, veio o Parque Gezi na Turquia, o levante da multidão de junho de 2013 no Brasil, a luta da Maidan na Ucrânia, tantas escaramuças contra o capitalismo globalizado por todo lado, até chegar na sublevação dos guarda-chuvas em Hong Kong, 2015.
\end{abstract}

Nesse trajeto, Dardot e Laval (2017, p. 18) expõem que a primeira teoria do comum teve origem nos trabalhos de Michael Hardt e Antonio Negri, cujo mérito histórico foi o de levar a reflexão do plano das experiências concretas do commons para uma concepção mais abstrata e politicamente ambiciosa do comum.

$\mathrm{Na}$ esteira do tratamento histórico do comum, é preciso ainda fazer menção a dois momentos que cunham de maneira negativa o termo, "duas 'tragédias' das quais é preciso se desvencilhar ou superar": a primeira delas relacionada à própria concepção do comum como tragédia e, a segunda, resumida na repulsa ao conceito em virtude das tristes experiências dos Estados comunistas (CRUZ, 2017, p. 5-6).

$\mathrm{Na}$ hipótese aventada no final da década de 1960 pelo ecologista americano Garrett Hardin, em ensaio intitulado "A tragédia dos Comuns", a ruína é um caminho inevitável para uma sociedade baseada na liberdade de acesso a bens comuns (HARDIN, 1968).

Desenvolvendo as ideias inicialmente postas pelo matemático Willian Forster Lloyd a respeito do controle de natalidade (LLOYD, 1833), advogou Hardin que o acesso livre a recursos limitados por meio de práticas de gestão comum e sem formas de controle público ou privado só poderia redundar na exploração exacerbada de tais recursos e na sua possível extinção. E, para elucidar seu pensamento, lançou mão de diversas situações que 
exemplificariam a constante má gestão dos comuns, incluindo a poluição, a destruição dos parques, parquímetros, roubos de banco e um campo de pastagem (HARDIN, 1968).

No exemplo do campo de pastagem, Hardin cita a história de um pasto aberto a todos, utilizado de modo comum por vários criadores de gado, aduzindo que, por determinado período, o compartilhamento poderia funcionar de modo satisfatório, diante do controle do número de homens e animais provocado por fatores como doenças, caça furtiva e guerras tribais. Porém, segundo o autor, quando referidos fatores são contornados e a estabilidade social é alcançada, cada criador, racionalmente decidindo, passa a acrescentar mais animais ao pasto, já que recebe o benefício total de cada animal adicional e arca apenas com uma fração dos malefícios do sobrepastoreio, o que termina por resultar na superexplocação da atividade e na consequente ruína da pastagem (HARDIN, 1968).

Diversos trabalhos envidaram esforços no sentido de contestar as conclusões de Garrett Hardin, merecendo destaque a contribuição da economista americana Elinor Ostrom, que, por meio de pesquisas e do estudo empírico de experiências de uso compartilhado em várias partes do mundo, demonstrou a viabilidade do comum (CRUZ, 2017, p. 6).

Em seu livro Governing the Commons (1990), obra que lhe rendeu o Prêmio Nobel de economia em 2009, Ostrom demonstra que a tragédia enunciada por Garret Hardin só se concretiza em um ambiente de falta de cooperação e que, assim sendo, seria plenamente possível gerir os recursos comuns de maneira sustentável, inclusive com resultados melhores do que nas situações de não cooperação entre os envolvidos.

Depois de Ostrom, principalmente, é possível dizer que, aos poucos, vai sendo aprofundado o estudo do comum, que evolui de sua noção tradicional, de mundo natural fora da sociedade, para uma noção ampliada, uma noção biopolítica, de instituição que permeia todas as esferas da vida (HARDT; NEGRI, 2016, p. 167-168).

A segunda tragédia do comum sintetiza-se no fracasso da tentativa de se estabelecer, em nome do bem comum, um regime econômico por meio do controle estatal, nos governos socialistas pós segunda guerra mundial, como o governo stalinista da União Soviética e o Maoísmo na China (CRUZ, 2017, p. 5-6).

Nessa perspectiva, o conceito do comum acabou por ser negativamente atrelado às experiências dos Estados comunistas, que, subvertendo a lógica de promoção do bem comum agasalhada no plano do comunismo como filosofia política, criaram, na prática, no comunismo real, alguns dos piores regimes da história, de repressão metódica e instituição do terror como forma de governo (DARDOT; LAVAL, 2017; COURTOIS et al, 1999). 
Para Cruz (2017, p. 7), dessa concepção do comunismo é preciso afastar-se com veemência ao falar do comum. E, na mesma senda, registram Dardot e Laval (2017, p. 100) que “a pretensa 'realização' do comum na forma de propriedade do Estado só pode ser a destruição do comum pelo Estado."

Em finalização ao tratamento histórico do comum, é curial dizer que este, nos dias atuais, encontra-se em evidência, em razão do trabalho de diversos autores e pesquisadores, em vários países, o que se infere pela literatura e manifestações cada vez mais abundantes a respeito do assunto, bem como, igualmente, em virtude da crescente conscientização acerca da crise socioeconômica e ambiental global e da possibilidade de um caminho sem volta.

Para além disso, leve-se em conta que na era da globalização tornam-se cada vez mais centrais as questões envolvendo o comum, na medida em que um dos efeitos básicos do mundo globalizado é a criação de um mundo comum, um mundo que, para o bem ou para o mal, todos compartilhamos, em que não há um "fora" (HARDT; NEGRI, 2016, p. 7-8).

No mais, apresenta-se relevante para o estudo proposto neste artigo uma estabelecer uma aproximação entre o comum e o Direito, o que se passa então a fazer.

\section{O COMUM E O DIREITO: APROXIMANDO OS MARCOS REGULATÓRIOS DO COMUM}

A relação entre o comum e o Direito é algo patente. E é possível concluir isso a partir de diversos ângulos de exame dessa comunicação, para além da aptidão de sua práxis instituinte no estabelecimento, produção e atualização de regras de Direito.

De início, cumpre gizar que, como já foi possível perceber até aqui, volta-se o comum contra a racionalidade neoliberal promotora de desigualdades que violentam a dignidade humana e a sustentabilidade. E, nessa medida, aqui reside uma vinculação entre o comum e o Direito, já que, nas palavras de Kerstenetzky (2002, p. 660), "a efetividade da igualdade de direitos civis e políticos é perturbada pela desigualdade econômica".

Se o comum lança-se a buscar redefinir a realidade atual, baseada na propriedade, no lucro e na desigualdade, se age para promover igualdade e se esta igualdade milita para efetivação de direitos, inegavelmente conecta-se com o Direito, ante a vocação deste para atuar na garantia dos direitos básicos do homem. Deveras, consoante Pérez Luño (1988, p. 45) destaca ao comentar a tese de Fernández Galiana, os Direitos Humanos devem ser garantidos pelo Direito Positivo. 
Mas é possível, ainda, ampliar a conclusão de Kerstenetzky, afirmando-se que não apenas a desigualdade econômica ofende direitos e que não somente direitos civis e políticos são atingidos por ela, como também a desigualdade presente na sociedade em seus outros variados aspectos é vilipendiadora de direitos que ultrapassam a esfera civil e política. A desigualdade, seja econômica, seja social, seja cultural, seja de que categoria for, é situação que causa abalo agressor dos direitos da pessoa humana (FELISMINO, 2009, p. 9157) e que, de outra ponta, faz nascer a resistência (CATANNI, 2009, p. 550), as lutas, a reivindicação do comum como elemento apto a promover igualdade e materializar direitos.

$\mathrm{O}$ próprio acesso à justiça, como direito à prestação da tutela jurisdicional e à possibilidade de ter em seu favor reconhecida a atuação do Direito no caso concreto, é estremecido pela desigualdade, podendo ser conectado, então, às possibilidades de atuação do comum. Consoante assevera FELISMINO (2009, p. 9142), "nos países periféricos, atingidos pela significativa desigualdade social, o problema do acesso à justiça está relacionado à busca pela efetivação de direitos básicos".

O combate à lógica proprietária em si, como um ponto específico e nuclear da racionalidade do comum, igualmente faz elo com o Direito, porquanto, ao levar a efeito essa frontal contestação ao direito de propriedade, põe-se o comum na linha de formatação de direitos relacionados ao uso compartilhado não exclusivo de bens e recursos, aptos a funcionar como instrumentos contra-hegemônicos à prática mercantilista e proprietária.

A alternativa do comum não é entre propriedade comum e propriedade privada, mas entre o inapropriável e a propriedade. O comum, que somente pode ser instituído como inapropriável, emana de uma atividade de pôr em comum que produz Direito, um Direito que não se pode identificar nem com um Direito Legislado, no sentido de algo advindo de uma autoridade soberana ou da vontade de um legislador, nem com um Direito consuetudinário, no sentido de algo elaborado por juristas ocupados de selecionar o que nos costumes é compatível com o direito de propriedade. Cuida-se então de um Direito representativo de uma norma de inapropriabilidade, capaz de criar novos direitos de uso contra o direito de propriedade (DARDOT; LAVAL, 2017, p. 244-245, 251, 341, 429 e 619).

Por outro lado, a relação entre o comum e o Direito pode ser estabelecida, ademais, a partir da percepção do uso do ferramental jurídico, como a elaboração de leis e a instituição de outras normas, em favor da lógica proprietária e em detrimento das práticas de vida em comum. Nesse sentido, Linebaugh (2013, p. 25) cita a transformação, em certas comunidades, 
de atividades antes legais e aceitas, a exemplo da caça e da pesca e do corte de árvores para a retirada de madeira, em atos contrários ao Direito.

Os bens comuns, da mesma sorte, sustentam ponte entre o comum e o Direito. Embora o comum seja algo muito mais amplo e complexo que a noção de bens comuns (WOLKMER; SCUSSEL, 2018, p. 81), tais bens são uma categoria que, por sua natureza, possuem disposição facilitada à formação de comuns, ante a propriedade comum existente (é intuitivo que será mais fácil a instituição de comuns sobre bens comuns do que sobre bens privados). E, nessa perspectiva, por estarem os bens comuns vinculados à efetivação de direitos fundamentais (GUIMARÃES, 2016, p. 23 e 131), possuem estes influxo e possibilidade de ação do comum, o que conecta o Direto a esse contexto.

Outro ponto de conexão entre o comum e o Direito está na democracia, na medida em que esta, por um lado, pode ser reconhecida com um elemento constitutivo dos comuns (SILVA, 2018, p. 15) e, por outro lado, é garantida pelo Estado de Direito (ROCHA, 2009, p. 380), compreendido, bebendo em Canotilho (1999, p. 11), como o Estado organizado de forma que sua atividade encontra-se determinada e limitada pelo Direito. Em outros termos, o Direito fundamenta e regula o Estado de Direito, o Estado de Direito garante a democracia, a democracia atua em prol do comum. Forma-se, pois, um ciclo comunicativo de interação que, ademais, reflete ao final na realização dos Direitos Humanos fundamentais.

Nesse sentido, cabe trazer a lume a lição de Silva (2004, p. 233):

[...] o regime democrático é uma garantia geral da realização dos direitos humanos fundamentais. Vale dizer, portanto, que é na democracia que a liberdade encontra campo de expansão. É nela que o homem dispõe da mais ampla possibilidade de coordenar os meios necessários à realização de sua felicidade pessoal. Quanto mais o processo de democratização avança, mais o homem se vai libertando dos obstáculos que o constrangem, mais liberdade conquista.

Diante dos pontos de entrelace já mencionados entre o comum e o Direito, nota-se sua íntima relação com os Direitos Humanos e com os direitos fundamentais. E, nesse caminhar, é lícito firmar, partindo da compreensão preconizada por Joaquín Herrera Flores acerca dos Direitos Humanos, que o comum integra e ao mesmo tempo esforça-se a materializar tais direitos, ficando aqui, uma vez mais, patenteada sua ligação com o jurídico.

Deveras, afirma Herrera Flores (2008, p. 12-13):

[...] nós definimos os direitos humanos como "processos de luta pela dignidade", ou seja, o conjunto de práticas sociais, institucionais, econômicas, políticas e culturais levadas a cabo pelos movimentos e grupos sociais em sua luta por um acesso igualitário e não hierarquizado a priori aos bens que fazem digna a vida que vivemos.

A coincidência da definição acima esposada com a representação do comum, notadamente quando entendido em um viés de significação de um regime de práticas, lutas e 
instituições em busca de um futuro diferente do atual (DARDOT; LAVAL, 2017, p. 18), marcado, como já se viu alhures, pelas desigualdades e ofensa à dignidade, é apta a nutrir a inferência de que o comum é um direito humano. Mas não apenas isso: ele integra os Direitos Humanos e, ao mesmo tempo, trabalha para materializar esses direitos, uma vez que "é produzido e é produtor" (CAVA, 2013, p. 24).

Vale destacar que a linguagem dos direitos e do Direito é frequente nas reivindicações e construções dos movimentos sociais, de maneira que este último pode ser pensado não apenas como norma, mas como campo de observação das relações sociais e produto dessas (BERNARDES, 2017, p. 281-282).

Para além do cenário delineado em face das considerações trazidas até este ponto, é essencial dizer que, de acordo com Dardot e Laval (2017, p. 618):

\begin{abstract}
O comum é, acima de tudo, uma questão de instituição e governo. [...] ao falarmos da instituição do comum, entendemos o comum em geral como objeto do ato de instituir, e não do comum como princípio: pois, embora o comum como princípio não tenha de ser instituído, mas simplesmente tem de ser reconhecido intelectualmente e na prática, todos os comuns têm de ser instituídos. Cada comum deve ser instituído por uma prática que abra certo espaço ao definir regras de seu funcionamento. Essa instituição deve continuar para além do ato pelo qual o comum é criado. Deve ser sustentada ao longo do tempo por uma prática que tenha a possibilidade de modificar as regras por ela própria estabelecidas. Chamamos essa prática de práxis instituinte. A práxis instituinte não é do âmbito da "gestão", no sentido de administração sem poder de decisão. Na realidade, a ilusão gestionária está associada à concepção naturalista do comum: se o comum estivesse inscrito na natureza e nas propriedades das coisas, seu reconhecimento poderia ser objeto de um consenso que estaria além do conflito dos interesses sociais. Ao contrário da "gestão", o "governo" cuida dos conflitos e tenta superá-los por meio de uma decisão relativa às regras. Portanto, a práxis instituinte é uma prática de governo dos comuns pelos coletivos que lhes dão vida.
\end{abstract}

Para Silva (2018, p. 69), Dardot e Laval reconhecem na "práxis instituinte do comum" uma atividade consciente de estabelecer ou produzir, contínua e ininterruptamente, regras de Direito a partir de certas condições preexistentes, sem, contudo, encerrar-se nelas, porquanto essa mesma atividade produz sempre novas condições, implicando na criação de sujeitos coletivos por automodificação dos atores do próprio curso da ação. Entendida dessa forma, a noção de práxis instituinte escaparia à alternativa entre poder instituinte e poder constituinte, consistindo em um agir comum que institui o comum e a partir do qual normas jurídicas são coproduzidas para sujeitar seus coprodutores durante a feitura da tarefa.

Daí a sustentação de Cava (2013, p. 24) no sentido de que o comum é institucionalizado por um Direito que garante sua realização e eficácia. É o denominado Direito do Comum.

Na mesma esteira, Lopes e Lima (2018, p. 898-899) afirmam que o comum exprime um princípio constitutivo de um novo Direito: o Direito do Comum revelado como 
coprodução de normas jurídicas que regulam uma nova relação entre pessoas e coisas, uma outra sociabilidade que não brota da noção de autoridade estatal. Um Direito que estampa, na dicção de Negri (2011, n.p.), a “equidade na coprodução de norma jurídica não estatal”.

Esse panorama é o que possivelmente anima a afirmação de Dardot e Laval (2017, p. 243) dando conta de que o comum é inegavelmente "uma questão de direito, ou seja, de determinação do que deve ser. O desafio é afirmar um direito novo, rejeitando as pretensões de um direito antigo".

Percebe-se, portanto, que o Direito do Comum claramente relaciona a temática do comum ao mundo jurídico, o que tem motivado, inclusive, vozes que já tratem da possibilidade de uma ordem jurídica do comum.

\section{CONCLUSÃO}

O comum não possui um tratamento conceitual homogêneo na literatura, ficando revelada, além do mais, uma significação que carrega certa complexidade. As compreensões acerca do comum passam desde o entender como algo transcendental, uma "condição ontológica do ser”, que não é produzido e que não é do campo da política, até sua concepção como princípio político, para além do público e do privado, ativador de processos de resistência e da produção, preservação e ampliação de comuns.

Essa última concepção parece prevalecer na literatura atual, de maneira que o comum passa a ser concebido não apenas como uma ideia, mas como um movimento real, uma verdadeira possibilidade de vivência, de novas formas de relação, cooperação, afeição, produção e vida, que carrega consigo uma nova ética, experimentada por novas subjetividades de resistência à racionalidade neoliberal do capitalismo de mercado e ao socialismo real.

Nessa perspectiva, o comum também é entendido como instrumento de inovação social, uma categoria cultural e prática que procura ver o mundo em termos diferentes. Retrata, basicamente, uma ordem que afirma que outro mundo é possível e que inclui recursos físicos e intangíveis de todo tipo, sendo identificado com maior precisão por um modelo que combina uma comunidade determinada e um conjunto de práticas sociais, valores e normas promovendo a gestão desses recursos.

Para o adequado tratamento conceitual do comum, ademais, impende compreender algumas outras categorias relacionadas ao termo, direta ou indiretamente, representadas por 
terminologias tais como: comuns, bens comuns, commons, terras comunais, commoning ou comuneiro, anticommons, bem comum da humanidade e global commons.

No que se refere ao percurso histórico do comum, conclui-se que é longo, marcado por lutas, por desafios, por sua ligação com tragédias e evidenciador do deferimento de maior importância e cuidado com o tema, na perspectiva de racionalidade de resistência contrahegemônica ao ideal neoliberal, apenas a partir do final dos anos 1960.

É já sob o contexto do neoliberalismo e capitalismo, pois, diante da permanência e intensificação das práticas de transferência de bens e recursos de uso comum e de espaços e serviços públicos para a propriedade pública e privada, que a abordagem do comum desponta e ganha relevo. São os anos 1990, nesse sentido, que decisivamente assinalam a genealogia do comum, ante o surgimento, na maior parte do mundo, de grupos militantes e correntes de pensamento que fortemente retomaram o fio da contestação da ordem dominante.

Nos dias atuais, o comum encontra-se em evidência, em razão do trabalho de diversos autores e pesquisadores, em vários países, devendo ser levado em conta, ademais, que um dos efeitos básicos da mundo globalizado é a criação de um mundo comum.

Por fim, constata-se que a relação entre o comum e o Direito é inarredável e exibida por diversos ângulos de análise, avultando, além do mais, sua práxis instituinte como uma atividade consciente de estabelecer ou produzir, contínua e ininterruptamente, regras de Direito a partir de certas condições preexistentes, sem, contudo, encerrar-se nelas.

O comum é, então, institucionalizado por um Direito que garante sua realização e eficácia, denominado Direito do Comum. Esse Direito é revelado como coprodução de normas jurídicas que regulam uma nova relação entre pessoas e coisas, uma outra sociabilidade que não brota da noção de autoridade estatal, podendo-se afirmar, por tudo isso, que o comum é inegavelmente uma questão de Direito, de determinação de dever-ser.

O Direito do Comum claramente liga a temática do comum ao campo jurídico, o que tem motivado, inclusive, vozes que já tratem da possibilidade de uma ordem jurídica do comum.

\section{REFERÊNCIAS}

BAKAN, Joel. A corporação: a busca patólogica por lucro e poder. São Paulo: Editora Novo Conceito, 2008.

BERNARDES, Márcio de Souza. A (re)invenção do comum no novo constitucionalismo latino-americano: ecologia política, Direito e resistência na América Latina. Florianópolis, 
UFSC, 2017. 309 f. Tese de Doutorado - Programa de Pós-Graduação em Direito, Universidade Federal de Santa Catarina, Florianópolis, 2017.

BOLLIER, David. Think like a commoner: a short introduction to the life of the commons. Gabriola Island (CA): New Society Publishers, 2014.

CANOTILHO, José Joaquim Gomes. Estado de Direito. 1. ed. Lisboa: Editora Gradiva, 1999.

CAPRA, Fritjof; MATTEI, Ugo. A revolução ecojurídica: o direito sistêmico em sintonia com a natureza e a comunidade. Tradução Jeferson Luiz Camargo. São Paulo: Cultrix, 2018.

CATANNI, Antonio David. Riqueza e desigualdades. Caderno CRH, Salvador, v. 22, n. 57, p. 547-561, Set./Dez. 2009

CAVA, Bruno. Metrópole como usina biopolítica - O trabalho da metrópole: transformações biopolíticas e a virada do comum. IHU On-line - Revista do Instituto Humanitas Unisinos, ed. 464, ano XV, p. 9-12, abr. 2015.

CAVA, Bruno. Pachukanis e Negri: do antidireito ao direito do comum. Revista Direito e Práxis, v. 4, n. 6, p. 2-30, 2013.

CERVEIRA, Luís Alexandre. "El derecho del común y los comuneros", da Espanha de Carlos V ao Paraguai colonial: permanências, apropriações e ressignificações. In: XXVII Simpósio Nacional de História, 2013, Natal. Anais [...]. São Paulo: ANPUH, 2013.

COMPARATO, Fábio Conder. A humanidade no século XXI: a grande opção. Revista CEJ, Brasília, n. 13, p. 187-198, jan./abr. 2001.

COURTOIS, Stéphane et al. O livro negro do comunismo: crimes, terror e repressão. Tradução Caio Meira. Rio de Janeiro: Bertrand Brasil, 1999.

CRUZ, Mariana de Moura. O novo vocabulário do Comum - ensaio para uma leitura póscolonial. In: XVII ENANPUR - Encontro Nacional da Associação Nacional de PósGraduação e Pesquisa em Planejamento Urbano e Regional, 2017, São Paulo. Anais [...]. São Paulo: Faculdade de Arquitetura e Urbanismo da Universidade de São Paulo, 2017.

DARDOT, Pierre; LAVAL, Christhian. Comum: ensaio sobre a revolução no século XXI. Tradução Mariana Echalar. 1. ed. São Paulo: Boitempo, 2017.

DEDECCA, Claudio Salvadori. Desigualdades, mas de qual falamos? Texto para Discussão. IE/UNICAMP, Campinas, n. 168, out. 2009.

FELISMINO, Lia Cordeiro. A Defensoria Pública como instrumento de efetivação do direito fundamental de acesso à justiça. In: XVIII Congresso Nacional do CONPEDI São Paulo-SP, 2009, São Paulo. Anais [...]. Florianópolis, CONPEDI, 2009. p. 9137-9162.

FIGUEIREDO, Janice. A construção do comum através da produção PEER. P2P \& Inovação, Rio de Janeiro, v. 1, n. 1, p. 25-44, set./dez. 2014. 
GUIMARÃES, Virgínia Totti. Direito à cidade, comuns urbanos e privatização de espaços públicos na Cidade do Rio de Janeiro: Os casos da Marina da Glória e do Campo de Golfe Olímpico. Rio de Janeiro, PUC-Rio, 2016. 275 f. Tese de Doutorado - Programa de PósGraduação em Direito, Departamento de Direito, Pontifícia Universidade Católica do Rio de Janeiro, Rio de Janeiro, 2016.

HARDIN, Garret. The tragedy of the commons. Revista Science, v. 162, n. 3859, dez./1968.

HARDT, Michael; NEGRI, Antonio. Bem-estar comum [recurso eletrônico]. Tradução Clóvis Marques. 1. Ed. Rio de Janeiro: Record, 2016.

HERRERA FLORES, Joaquín. Entrevista com Joaquim Herrera Flores. Constituição e Democracia. Junho de 2008. Fls. 12-13. UnB.

HOUART, François. Dos bens comuns ao "bem comum da humanidade". In: Conferência "Dos bens comuns ao Bem Comum da Humanidade", 2011, Roma. Tradução Conceição Rosa de Lima Conceição. Anais [...]. Bruxelas, Fundação Rosa de Luxemburgo, 2011.

KERSTENETZKY, Celia Lessa. Por que se importar com a desigualdade. DADOS - Revista de Ciências Sociais, Rio de Janeiro, v. 45, n. 4, p. 649 a 675, 2002.

LIMA, Danilo Pereira; LOPES, Ziel Ferreira. Direito do comum em Canudos. Revista Direito \& Práxis, Rio de Janeiro, v. 9, n. 2, p. 890-927, 2018.

LINEBAUGH, Peter. El manifesto de la Carta Magna: comunes y libertades para el pueblo. Traducción Uaiza Hernández Velázquez y Asrtor Díaz Simón. 1. ed. Madrid: Traficantes de Sueños, 2013. Licencia Creative Commons.

LLOYD, William Forster. Two Lectures on the Checks to Population. Oxford, England: Oxford University Press, 1833.

MEDEIROS, Dérika Correia Virgulino de. Comum: a palavra do nosso tempo. In: $40^{\circ}$ Congresso Brasileiro de Ciências da Comunicação, 2017, Curitiba. Anais [...]. São Paulo: ITERCOM - Sociedade brasileira de Estudos Interdisciplinares da Comunicação, 2017.

MENDES, Alexandre Fabiano. Para além da "Tragédia do comum": conflito e produção de subjetividade no capitalismo contemporâneo. Rio de Janeiro, UERJ, 2012. 188 f. Tese de Doutorado - Programa de Pós-Graduação em Direito, Universidade do Estado do Rio de Janeiro, Rio de Janeiro, 2012.

NEGRI, Antonio. O direito do comum: o que existe na fronteira entre o público e o privado? Tradução de Sérgio Rauber. Disponível em: http://uninomade.net/tenda/o-direito-do-comumo-que-existe-na-fronteira-entre-o-publico-e-o-privado/. Acesso em: 23 mar. 2019.

OLIVEIRA, Michele Aparecida. O direito ao meio ambiente sadio na sociedade capitalista. In: $6^{\circ}$ Seminário Nacional Estado e Políticas Sociais e $2^{\circ}$ Seminário de Direitos Humanos, 2014, Toledo. Anais [...]. Toledo: Universidade Estadual do Oeste do Paraná, 2014.

OSTROM, Elinor. Governing the commons: the evolution of institucions for collective action. New York: Cambridge University Press, 1990. 
OXFAM. Uma economia para os 99\%. Documento informativo da Oxford Committee for Famine Relief - OXFAM. OXFAM Internacional, Oxford, jan. 2017.

PASTOR, Jaime. Lo(s) común(es), lo público y lo estatal. Viento Sur, n. 130, nov./2013.

PERALTA, Nelissa. A contribuição da teoria da escolha racional para o debate sobre o uso comum dos recursos naturais. UAKARI, v. 6, n.1, p. 61-72, jun./2010.

PÉREZ LUÑO, Antonio Enrique. Los derechos fundamentales. Madrid: Tecnos, 1988.

REBOUÇAS, Marcus Vinícius Parente; PARENTE, Analice Franco Gomes. Capitalismo e desigualdade econômica na perspectiva empírica de Simon Kuznets. In: XXVII Congresso Nacional do CONPEDI Porto Alegre-RS, 2018, Porto Alegre. Anais [...]. Florianópolis, CONPEDI, 2018. p. 185-205.

ROCHA, Manoel Ilson Cordeiro. Pós-Modernidade e crise do Estado Moderno: o ocaso do constitucionalismo liberal. Nucleus, v. 6, n. 2, out./2009.

RUSCHEL, Caroline Vieira; PORTANOVA, Rogério da Silva. Global Commons e confusão gerada a partir da nomenclatura: esclarecendo os diferentes conceitos dos comuns. In: $23^{\circ}$ Congresso Brasileiro de Direito Ambiental, 2018, São Paulo. Anais [...]. São Paulo: Instituto O Direito por um Planeta Verde, 2018. p. 295-306.

SCHEFFER, Fernando. Desenvolvimento sustentável e modernidade: uma incompatibilidade anunciada. UDESC - Universidade do Estado de Santa Catarina. Disponível em: http://www.apec.unesc.net/VI_EEC/sessoes_tematicas/Tema1Desenvolvimento\%20Meio\%20Ambiente/Artigo-3-Autoria.pdf. Acesso em: 23 mar. 2019.

SILVA, Ana Claudia Milani e. Ocupar, resistir, fazer-comum: reflexões sobre a democracia constitucional. Curitiba, UFPR, 2018. 141 f. Dissertação de Mestrado - Programa de Pós Graduação em Direito, Universidade Federal do Paraná, Curitiba, 2018.

SILVA, José Afonso da. Curso de direito constitucional positivo. 23 ed. São Paulo: Malheiros, 2004.

TEIXEIRA, Antonio Claudio Engelke Menezes. O comum como linguagem política. Revista da Associação Nacional dos Programas de Pós-Graduação em Comunicação - E-compós, Brasília, v. 20, n. 3, set./dez. 2017.

WOLKMER, Maria de Fátima Schumacher; SCUSSEL, Evelyn. A questão do "comum" no constitucionalismo latino-americano. Revista Culturas Jurídicas, v. 5, v. 11, p. 79-104, mai/ago 2018. 